\title{
The co-occurrence of substance P-like immunoreactivity and dynorphin-like immunoreactivity in striatopallidal and striatonigral projection neurons in birds and reptiles
}

\author{
ANTON REINER \\ Department of Anatomy and Cell Biology, The University of Michigan, Ann Arbor, MI 48109 (U.S.A.)
}

(Accepted December 17th, 1985)

Key words: substance $\mathrm{P}$ — dynorphin - co-occurrence — striatonigral - striatopallidal - basal ganglion - bird - reptile

\begin{abstract}
Using an immunofluorescence procedure that allows the simultaneous labeling of tissue for two different antigens, substance P-like immunoreactivity (SPLI) and dynorphin-like immunoreactivity (DLI) were observed to co-occur extensively in striatal neurons of the avian and reptilian basal ganglia and in fibers and terminals in the projection targets of the avian and reptilian striata. Thus, SPLI and DLI apparently co-occur extensively in striatopallidal and striatonigral projection neurons of the avian and reptilian basal ganglia. Since basal ganglia organization is fundamentally similar among amniotes, the present results suggest that SPLI and DLI may also cooccur extensively in striatal neurons in mammals.
\end{abstract}

In birds, reptiles and mammals, a neuropeptide highly similar or identical to substance $\mathrm{P}(\mathrm{SP})$ is present in striatopallidal and striatonigral projection neurons ${ }^{4,14.18 .22,24-26}$. These SP-containing striatal neurons appear to represent a distinct subpopulation of the medium-sized neurons that make up the vast majority of the striatal neurons present in the basal ganglia ${ }^{4} \cdot 10,22.25$. Several recent studies have shown that members of the dynorphin family of peptides also appear to be present in striatopallidal and striatonigral projection neurons in the basal ganglia of birds, reptiles and mammals ${ }^{20-23,27.28}$. The present studies in White Carneaux pigeons and red-eared turtles were carried out to determine whether the dynorphinergic striatal neurons represent a neuronal population that is distinct from the population of SP-containing striatal neurons or whether dynorphin and SP are contained in the same striatal neurons.

An immunofluorescence double-labeling procedure was used that allows two different tissue antigens to be simultaneously and differentially labeled with two different fluorophores ${ }^{8,19,24,30}$. This doublelabeling procedure, which has been referred to as the simultaneous immunofluorescence procedure, has been described previously in greater detail ${ }^{8.24}$. In the present study, SP-containing neurons and fibers were labeled using a rat monoclonal antibody (Accurate Chemical and Scientific Corporation) in conjunction with a tetramethylrhodamine isothiocyanate (TRITC)-conjugated secondary antiserum (goat anti-rat $\operatorname{lgG}$ ), while dynorphinergic neurons and fibers were labeled using a rabbit antiserum against Dynorphin $\mathrm{A}_{1-17}$ (generously provided by $\mathrm{L}$. Terenius of Uppsala University, Sweden) in conjunction with a fluorescein isothiocyanate (FITC)-conjugated secondary antiserum (goat anti-rabbit $\operatorname{lgG}$ ). Animals received intraventricular injections of colchicine (100 $\mu \mathrm{g}$ in pigeons and $50 \mu \mathrm{g}$ in turtles) to enhance perikaryal immunoreactivity. Following a postinjection survival time of $36-48 \mathrm{~h}$ (pigeons) or 96-120 (turtles), the animals were deeply anesthetized (ketamine for turtles and 35\% chloral hydrate for pigeons) and their brains fixed by transcardial perfusion as described previously ${ }^{24-26}$. The brains were then sectioned frozen at $40 \mu \mathrm{m}$ and processed according to the simultaneous immunofluorescence procedure $^{8,24}$. Tissue incubations were carried out by first incubating tissue in a primary antisera cocktail containing the anti-SP antibody (at a 1:1000 dilution) and the anti-Dynorphin $A_{1-17}$ antiserum (at a 1:250

Correspondence: A. Reiner, Department of Anatomy and Cell Biology, The University of Michigan, Ann Arbor, MI 48109, U.S.A. 


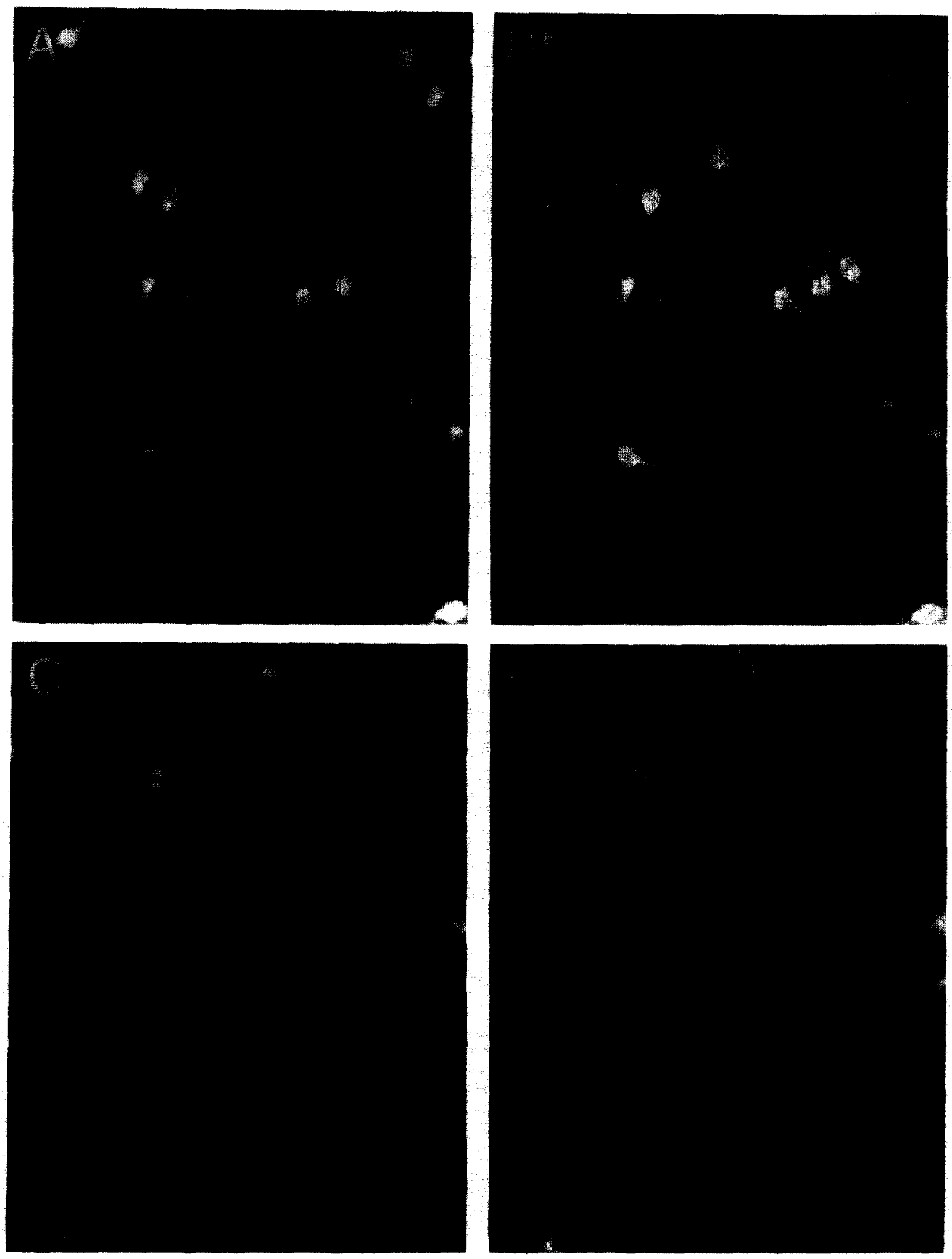

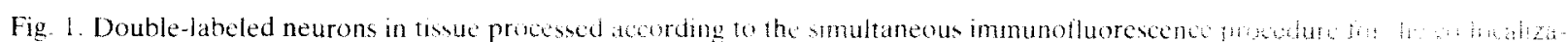

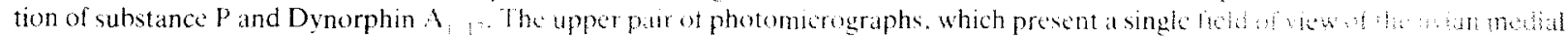

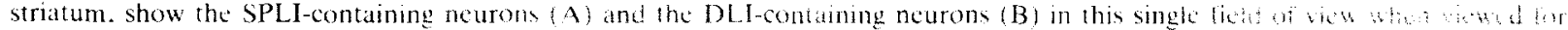

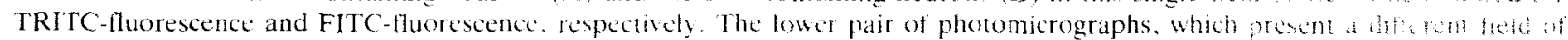

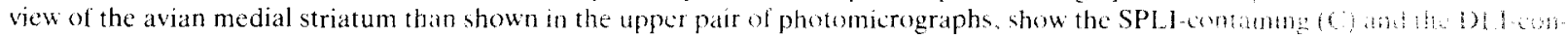

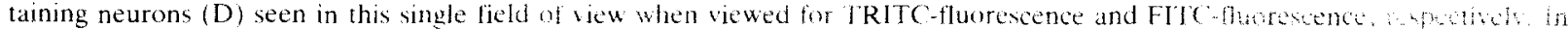

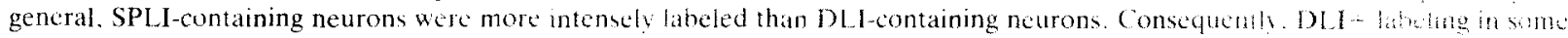

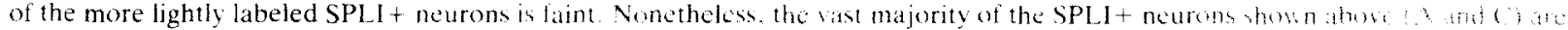
also clearly labeled for DLI ( $B$ and $D)$. The striatal neurons shown have a somal diameler of $101-15$ am? 
dilution), followed by an incubation in a secondary antisera cocktail containing each of the secondary antisera at a 1:50 dilution. The primary antisera used here have been previously shown to be specific for the C-terminus of SP and the C-terminus of Dynorphin $\mathbf{A}_{1-17}$, respectively ${ }^{6,27,28}$. To prevent any crossreactive labeling of enkephalinergic neurons by the dynorphin antiserum, the primary antisera cocktail was blocked with $100 \mu \mathrm{mol}$ leucine-enkephalin in all experiments.

Two types of controls ensured that the double-labeling observed in the present study was not the byproduct of unintended antisera cross-reactivity. First, numerous neurons labeled only for substance $P$ or only for Dynorphin $A_{1-17}$ were observed outside the basal ganglia (particularly in the hypothalamus). Such single-labeled neurons would not have been observed if either of the secondary antisera cross-reacted with each other or with their non-targeted primary antiserum. Secondly, the specificity of the doublelabeling was confirmed by a control study in which tissue was incubated in the primary antisera cocktail blocked with either $100 \mu \mathrm{mol}$ SP or $100 \mu \mathrm{mol}$ Dynorphin $\mathrm{A}_{1-17}$ (as well as with $100 \mu \mathrm{mol}$ leucine-enkephalin), followed by normal incubation in the secondary antisera cocktail. In tissue processed in this fashion, only TRITC-substance P-labeling was observed when the primary antisera cocktail was blocked with Dynorphin $\mathrm{A}_{1-17}$ and only FITC-Dynorphin $\mathrm{A}_{1-17^{-}}$-labeling was observed when the primary antisera cocktail was blocked with substance $P$. The intensity and distribution of the labeling observed for the unblocked antiserum was identical to that observed for that antiserum when the antisera cocktail was not blocked. This result indicates that: (1) the anti-substance $\mathrm{P}$ antibody does not cross-react with Dynorphin $A_{1-17}$ and the anti-Dynorphin $A_{1-17}$ antiserum does not cross-react with substance $P,(2)$ neither of the secondary antisera bind to their non-targeted primary antiserum, and (3) the secondary antisera do not bind to each other.

The striatum in pigeons and turtles consists of two subdivisions: (A) a medial subdivision, termed the lobus parolfactorius (LPO) in pigeons and area $d$ in turtles, and (B) a lateral subdivision, termed the paleostriatum augmentatum (PA) in both pigeons and turtles. In both species, the medial striatum projects to tegmental catecholaminergic cell groups corre-
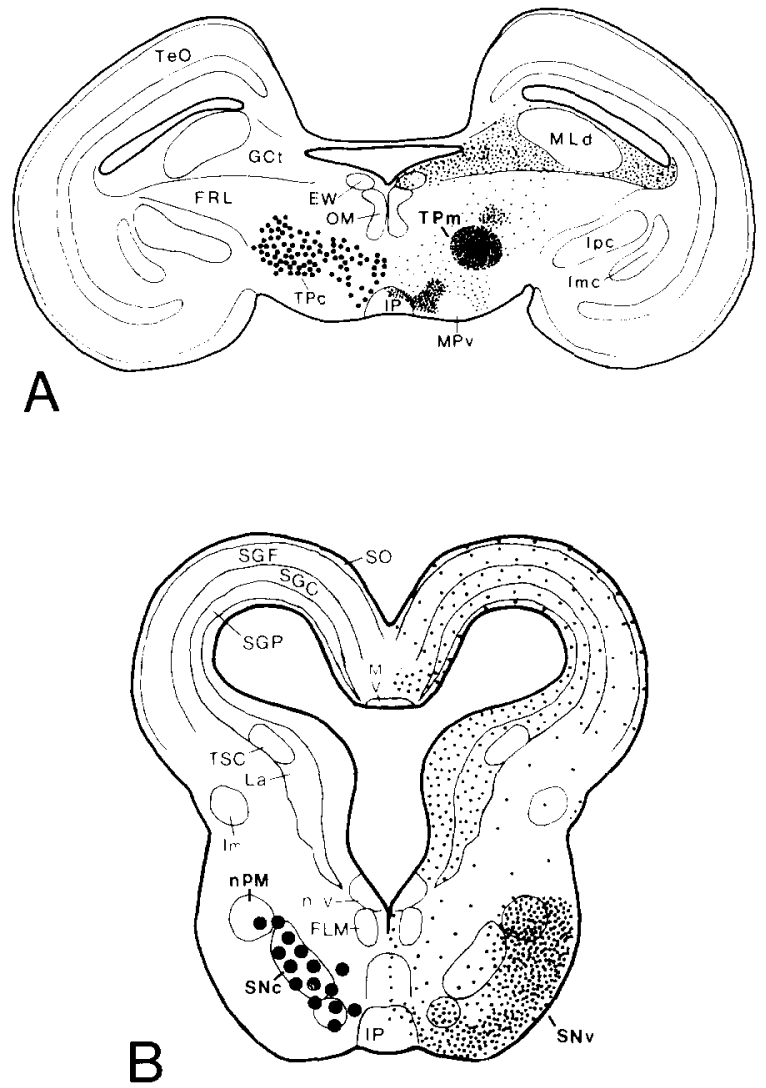

Fig. 2. Schematic line drawings of transverse sections through a midmesencephalic level illustrating the location and organization of the 'nigral' cell fields of the tegmentum in pigeons (A) and turtles (B). The right side of each schematic illustrates the location and density of the SP-containing fibers (SP-containing fibers in the pigeon tectum, although abundant, are not illustrated). The left side of each schematic shows the distribution of the dopaminergic neurons (filled circles) at this level of the midbrain. The TPc of pigeons and the SNc of turtles correspond to the substantia nigra, pars compacta of mammals. while the TPm of pigeons and the $\mathrm{SNv}$ of turtles correspond to the substantia nigra, pars reticulata of mammals. Abbreviations: EW, nucleus of Edinger-Westphal; FLM, medial longitudinal fasciculus; FRL, lateral reticular formation: $\mathrm{GCt}$, central grey; IP, interpeduncular nucleus; Im, nucleus isthmi, pars rostralis; Imc, nucleus isthmi, pars magnocellularis; Ipc, nucleus isthmi, pars parvocellularis; La, nucleus laminaris of the torus semicircularis; MLd, nucleus mesencephali lateralis, pars dorsalis; MPv, nucleus profundus mesencephali, pars ventralis; $M V$, mesencephalic nucleus of the trigeminal nerve; nIV. trochlear nucleus; nPM, nucleus profundus mesencephali; OM, oculomotor nucleus; SGF, stratum griseum et fibrosum superficiale of the optic tectum; SGC, stratum griseum centrale of the optic tectum; SGP, stratum griseum profundum of the optic tectum; SNc. substantia nigra, pars compacta; SNv, substantia nigra pars ventralis; SO, stratum opticum of the optic tectum; TeO, optic tectum; TPc, nucleus tegmentipedunculopontinus, pars compacta; TPm. nucleus tegmentipedunculopontinus, pars medialis; TSC, torus semicircularis. 

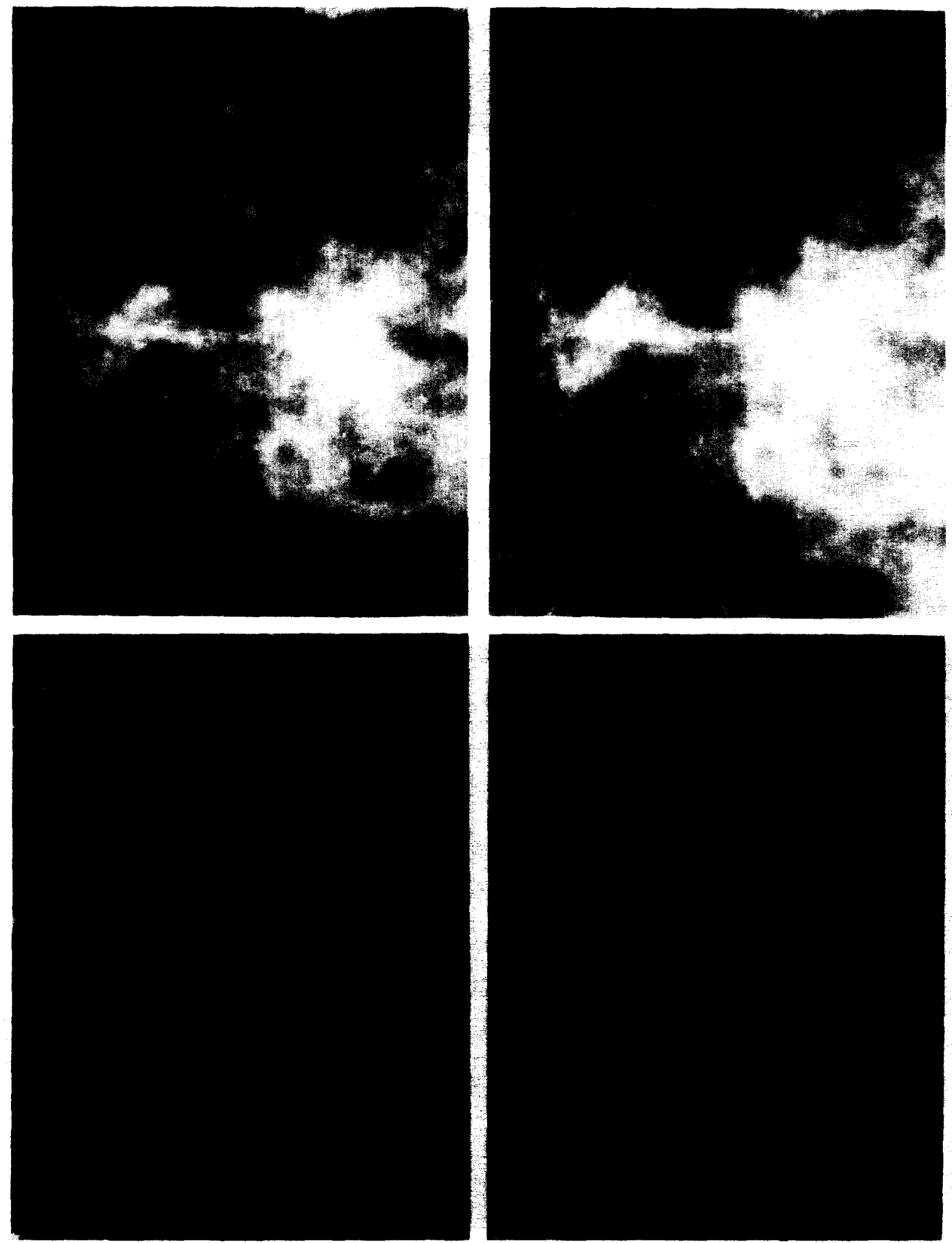

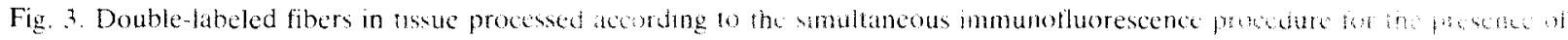

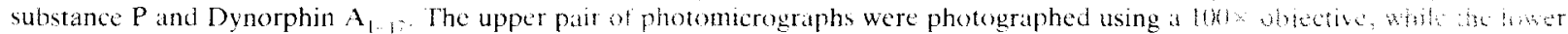
pair were photographed using a $50 \times$ objective. The upper pair show TRITC-labeled SPLI-containing fibers and termmith in the the solateral edge of the substantia nigra of turtle $(A)$ and the DLI-containing fibers in the same field of view (B). The (nstrall latheting pattern for SPLI is largely identical to that for DI.I and numerous individual boutons can be observed to be labeled in both phownicrographs. The lower pair of photomicrographs show IRITC-labeled SPLI-containing fibers and terminals in the turtle gionus patious (C) and the DLI-containing fibers and terminals observed in the same field of view (D). As in the cane whe upper pur whom phom crographs, the overall labeling patterns in the pair of photomicrographs are largely identical and numerou individual boungs sun be observed to be labeled in both photomicrographs 
sponding to the ventral tegmental area (AVT), the substantia nigra (SN) and the nucleus tegmentipedunculopontinus (TP) of mammals ${ }^{4,13,25}$. The PA in both birds and reptiles projects to the portion of the basal ganglia corresponding to the mammalian globus pallidus ${ }^{2,3}$. In the present study, numerous SPlike immunoreactivity (SPLI)-containing neurons and numerous dynorphin-like immunoreactivity (DLI)-containing neurons were observed within the striata of colchicine-treated pigeons and turtles (Fig. 1). In both pigeons and turtles, these neurons possess medium-sized perikarya $(10-15 \mu \mathrm{m})$. Within the medial striatum in both species, nearly all $(95-99 \%)$ of the labeled cells examined for the co-occurrence of SPLI and DLI contained both SPLI and DLI (Fig. 1). The major tegmental projection of the medial striatum in birds and reptiles (as is also true in mammals) is to the nigral cell field of the tegmentum. The SPLIand DLI-containing striatal projections to this nigral cell field (termed TP in birds and termed SN in turtles) terminate most densely in a portion of the nigral cell field that is relatively poorer in dopaminergic neurons than other portions of the nigral cell field $^{4,13,25}$. In pigeons, this SPLI-rich and DLI-rich field is located within dorsomedial TP (TPm), while in turtles this field is located within the ventrolateral substantia nigra (SNv) (Fig. 2). The avian TPm and the turtle SNv thus appear comparable to the pars reticulata portion of the mammalian substantia nigra ${ }^{30}$, based on the similarities in the densities of SPLI-containing fibers and DLI-containing fibers observed in these regions. In double-labeled avian and reptilian tissue examined at low power, the fiber labeling pattern for SPLI within the tegmental target areas (most strikingly the avian TPm and the reptilian SNv) of the medial striatum was nearly identical to that observed for DLI. High-power examination revealed that SPLI and DLI clearly co-occurred in the majority of the labeled fibers and boutons in the projection fields of the medial striatum (Fig. 3), although the large numbers and dense packing of the labeled fibers and terminals within these tegmental fields made it impractical to examine all fibers and terminals in singlefields of view for the co-occurrence of SPLI and DLI. The observation of such extensive co-occurrence of SPLI and DLI within medial striatal neurons and in fibers and boutons in medial striatal projection targets suggests that many (if not all) of the medial stria- tal neurons in which SPLI and DLI co-occur are striatonigral (or more broadly striatotegmental) projection neurons.

Within the lateral striatum in both pigeons and turtles, the co-occurrence of SPLI and DLI was extensive, but not as extensive as in the medial striatum. Although nearly all (95-99\%) of the DLI-containing neurons observed in the lateral striatum contained SPLI, only $70-85 \%$ of the SPLI-containing neurons contained observable DLI. Both single-labeled neurons and double-labeled neurons possessed mediumsized perikarya. Within the projection target of the lateral striatum, termed the paleostriatum primitivum in pigeons and the globus pallidus in turtles ${ }^{2-4.22,25.26}$, nearly identical labeling patterns for SPLI and DLI were observed in double-labeled material examined at low power. This was also observed to be the case in the ventral paleostriatum, which is rich in both SPLI-containing fibers and DLI-containing fibers and is comparable to the mammalian ventral pallidum ${ }^{13.25}$. When examined at high power, the vast majority of the labeled fibers and boutons in the paleostriatum primitivum and ventral paleostriatum of pigeons and in the globus pallidus and ventral paleostriatum of turtles were found to be clearly labeled for the presence of both SPLI and DLI (Fig. 3). Since lateral striatal neurons are reported to be the source of projections to the pallidal cell field of the avian and reptilian basal ganglia, the present results indicate that many (if not all) of the lateral striatal neurons in which SPLI and DLI co-occur are striatopallidal projection neurons.

Thus, the present results indicate that SPLI and DLI co-occur extensively in striatonigral and striatopallidal projection neurons in birds and reptiles. Whether the SPLI-only neurons and DLI-only neurons observed in the present study are neuronal populations that are distinct from those containing both SPLI and DLI or whether they simply contained one peptide in an amount that was subthreshold for immunohistochemical detection is at present uncertain.

Since the basal ganglia of all amniotes share a number of characteristics in common, particularly with respect to striatal organization ${ }^{22}$, the extensive cooccurrence of SPLI and DLI in striatal neurons of birds and reptiles suggests that SPLI and DLI may also co-occur extensively in striatal neurons in mammals. Although the possibility that SPLI and DLI co- 
occur extensively in striatal neurons in mammals has not been examined directly by double-label studies. the inference of such co-occurrence is consistent with the results of several single-label studies in mammals, which show that striatal neurons, pallidal fibers and nigral fibers containing SPLI have highly similar distributions to those containing DLI ${ }^{9.16 .18 .2 \%}$. Further, since SP and the related tachykinin. substance $K$ (SK), appear to be present in the same striatal neurons in mammals ${ }^{17}$, the present results suggest that both SK and SP co-occur with dynorphin in mammalian striatal neurons. Separate SK-like and SP-like peptides have not, however, been identified in nonmammals; and thus, it is unknown if both an SK-like and an SP-like peptide co-occur with dynorphin in striatal neurons in birds and reptiles. Medium-sized striatal neurons in all amniotes are also known to contain GABA and enkephalin 19,10.22.23. Several investigators have reported that the vast majority of the enkephalinergic striatal neurons (and their fibers) in mammals contain glutamic acid decarboxylase (GAD), the synthetic enzyme for $\gamma$-aminobutyric acid (GABA) $)^{1.31}$ and that these enkephalin-containing/GABAergic neurons comprise over $40 \%$ of the medium-sized striatal neurons in mammals. These studies have further reported that many additional neurons (and their fibers) in the mammalian striatum contain GAD but not enkephalin. In birds also, enkephalinergic as well as non-enkephalinergic striatal neurons have been observed to contain GABA (using an anti-GABA antiserum courtesy of T.G. Kingan of Columbia University, NY) (A. Reiner, unpublished observation). Although it seems possible that at least some of the non-enkephalincontaining GABAergic striatal neurons contain SP/ dynorphin, no published data are available on this point. The results of several previous studies do in-

1 Afsharpour, G., Penny, G.R. and Kitai, S.T., Glutamic acid decarboxylase, leucine-enkephalin, and substance $P$ immunoreactive neurons in the neostriatum of the rat and cat, Soc. Neurosci. Abstr. 10 (1984) 702.

2 Brauth, S.E., Ferguson, J.L and Kitt, C.A., Prosencephalic pathways related to the paleostriatum of the pigeon, $\mathrm{Co}$ lumba livia, Brain Research, 147 (1978) 205-221.

3 Brauth, S.E. and Kitt, C.A., The paleostriatal system of Caiman crocodilus, J. Comp. Neurol., 189 (1980) 437-465.

4 Brauth, S.E., Reiner, A., Kitt, C.A. and Karten, H.J., The substance P-containing striato-tegmental path in reptiles: an immunohistochemical study. J. Comp. Neurol., 219 (1983) 305-327 dicate, however, that it is unlikely that enkephatin co-occurs with SP/dynorphin to any great extent in neurons of the avian and mammalian striata Thus, enkephalin-containing/GABAergic neurons and SPLl-containing/DLI-containing neurons ap. pear to make up two major distinct populations of striatal neurons in the amniote basal ganglia.

The functional significance of the co-occurrence of SPLI and DLI is uncertain. Opioid peptides, including dynorphin peptides, have been reported to inhibit substantia nigra neurons ${ }^{11.24}$. In contrast. several studies indicate that SP (as well as SK) excites nigral neurons 7.12 .15 . These results suggest that $\mathrm{SP}$ and $\mathrm{dy}$ norphin may oppose one another in their actions in the mammalian substantia nigra. In this light. the cooccurrence of SP and dynorphin in striatonigral projection neurons appears paradoxical. Such co-occurrence would not, however, be paradoxical under either of two non-mutually exclusive circumstances: (1) if SP and dynorphin are released from nigral terminals under different conditions. or (2) if SP and dynorphin influence different nigral neurons. Whether or not the roles of SP and dynorphin within the globus pallidus are similar to those in the substantia nigra is at present uncertain. Although much further research is required to elucidate the functional significance of SP/dynorphin co-occurrence in striatal neurons, the presence of such co-occurrence clearly indicates that the neurotransmitter/neuromodulator interactions of individual striatal neurons with their projection targets is much more complex than previously realized.

Special thanks are in order to Gary Henderson for technical assistance and to Dr. M.G. Honig for valuable comments on the manuscript. This research was supported by Grant NS-19620.

5 Chesselet, M.-F. and Graybiel, A.M., Met-enkephalin-like and dynorphin-like immunoreactivities of the basal ganglia of the cat, Life Sci., 33 (1983) 37--40.

6 Cuello, A.C., Galfre, G. and Milstein, C., Detection of substance $\mathrm{P}$ in the central nervous system by a monoclonal antibody, Proc. Natl. Acad. Sci. U.S.A.. 76 (1979) $3532-3536$.

7 Davies. J. and Dray, A., Substance P in the substantia nigra, Brain Research, 107 (1976) 623-627.

8 Erichsen, J.T., Reiner, A. and Karten, H.J., Co-occurrence of substance $P$-like and leu-enkephalin-like immunoreactivities in neurons and fibers of avian nervous system, Nature (London), 295 (1982) 407-410. 
9 Graybiel, A.M. and Chesselet, M.-F., Compartmental distribution of striatal cell bodies expressing [Met]enkephalinlike immunoreactivity. Proc. Natl. Acad. Sci. U.S.A., 81 (1984) 7980-7984.

10 Graybiel, A.M. and Ragsdale, C.W., Jr., Fiber connections of the basal ganglia. In M. Cuenod, G.W. Kreutzberg and F.E. Bloom (Eds.), Development and Chemical Specificity of Neurons, Elsevier, Amsterdam, 1979. pp. $239-283$.

11 Hommer, D.W. and Pert, A., The actions of opiates in the rat substantia nigra: an electrophysiological analysis, Peptides, 4 (1983) 603-608.

12 Innis, R.B., Andrade, R. and Aghajanian, G.K., Substance $\mathrm{K}$ excites substantia nigra neurons in rat, Soc. Neurosci. Abstr., 10 (1984) 812.

13 Kitt, C.A. and Brauth, S.E., Projections of the paleostriatum upon the midbrain tegmentum in the pigeon, Neuroscience, 6(1981) 1551-1566

14 Krause, J.E., Reiner, A.J., Advis, J.P. and McKelvy, J.F., In vivo biosynthesis of $\left[{ }^{35} \mathrm{~S}\right]$ - and $\left[{ }^{3} \mathrm{H}\right]$ substance $P$ in the striatum of the rat and their axonal transport to the substantia nigra, J. Neurosci., 4 (1984) 775-785.

15 Lanthorn, T.H., O'Donohue, T.L., Shults, C.W., Chase, T.N. and Walters, J.R., The effects of iontophoretically applied substance $\mathrm{K}$ (SK) on single unit activity in the rat substantia nigra (SN), Soc. Neurosci. Abstr, 10 (1984) 1121.

16 McLean, S., Bannon, M., Zamir, N. and Pert, C.B., Comparison of the projections of substance $\mathbf{P}$ and dynorphin to the rat substantia nigra: a radioimmunocytochemical and biochemical study, Soc. Neurosci. Abstr., 10 (1984) 589

17 Nawa, H. . Hirose, T., Takashima, H., Inayama, S. and Nakanishi, S., Nucleotide sequences of cloned cDNA for two types of bovine brain substance P precursor, Nature (London), 306 (1983) 32-36.

18 Nicoll, R.A., Schenker, C. and Leeman, S.E., Substance P as a transmitter candidate, Ann. Rev. Neurosci., 3 (1980) $227-268$.

19 Oertel. W.H., Riethmuller, G., Magnaini, E., Schmechel, D.E., Weindl, A., Gramsch, C. and Herz, A., Opioid peptide-like immunoreactivity in GABAergic neurons of rat neostriatum and central amygdaloid nucleus, Life Sci., 33 (1983) $73-76$.
20 Palkovits, M., Brownstein, M.J. and Zamir, N., On the origin of Dynorphin A and alpha-neo-endorphin in the substantia nigra, Neuropeptides, 4 (1984) 193-199.

21 Reiner, A., Comparative studies of opioid peptides: enkephalin distribution in turtle central nervous system, Soc. Neurosci. Abstr., 9 (1983) 439.

22 Reiner, A., Brauth, S.E. and Karten, H.J., Evolution of the amniote basal ganglia, TINS, 7 (1984) 320-325.

23 Reiner, A., Davis, B.M., Brecha, N.C. and Karten, H.J., The distribution of enkephalin-like immunoreactivity in the telencephalon of the adult and developing domestic chicken, J. Comp. Neurol., 228 (1984) 245-262

24 Reiner, A., Eldred, W.D., Beinfeld, M.C. and Krause, J.E., The co-occurrence of a substance P-like peptide and cholecystokinin-8 in a fiber system of turtle cortex, J. Neurosci., 5 (1985) 1527-1544.

25 Reiner, A., Karten, H.J. and Solina, A.R., Substance P: localization within paleostriatal-tegmental pathways in the pigeon, Neuroscience, 9 (1983) 61-85.

26 Reiner, A., Krause, J.E., Keyser, K.T., Eldred, W.D. and McKelvy, J.F., The distribution of substance $P$ in turtle nervous system: a radioimmunoassay and immunohistochemical study, J. Comp. Neurol., 226 (1984) 50-75.

27 Vincent, S.R., Hökfelt, T., Christensson, I. and Terenius, L., Dynorphin-immunoreactive neurons in the central nervous system, Neurosci. Lett., 33 (1982) 185-190.

28 Vincent, S.R., Hökfelt, T., Christensson, I. and Terenius, L., Immunohistochemical evidence for a dynorphin immunoreactive striato-nigral pathway, Eur. J. Pharmacol., 85 (1982) 251-252

29 Walker, J.M. and Friederich, M.W., Electrophysiological and behavioral actions of dynorphin in the substantia nigra, Soc. Neurosci. Abstr., 11 (1985) 1163.

30 Wessendorf, R. and Elde, R.P., Characterization of an immunofluorescence technique for the demonstration of coexisting neurotransmitters within nerve fibers and terminals, J. Histochem. Cytochem., 33 (1985) 984-994.

31 Zahm, D.S., Zaborszky, L., Alones, V.E. and Heimer, L., Evidence for the coexistence of glutamate decarboxylase and Met-enkephalin immunoreactivities in axon terminals of rat ventral pallidum. Brain Research, 325 (1985) $317-321$ 